This article is (c) Emerald Group Publishing and permission has been granted for this version to appear here (http://epress.lib.uts.edu.au/research/handle/10453/10420). Emerald does not grant permission for this article to be further copied/distributed or hosted elsewhere without the express permission from Emerald Group Publishing Limited.' 


\section{Understanding and resolving the global problematique: Assessing the balance between progressive and socially conservative foresight}

\section{Richard Slaughter and Chris Riedy}

Professor Richard A Slaughter is a writer, practitioner and innovator in Futures Studies and Applied Foresight. He is the author or editor of some 20 books and many papers on a variety of futures topics. He is currently Director of Foresight International, an independent company dedicated to building the Futures field and facilitating the emergence of social foresight.

Foresight International, PO Box 793, Indooroopilly, Qld., 4068, Australia.

Email: rslaughter@ozemail.com.au

Web: http://www.foresightinternational.com.au

Weblog: http://www.richardslaughter.com.au

Tel: +61 (0)419134900

Dr Chris Riedy is a Research Director at the Institute for Sustainable Futures, University of Technology, Sydney.

PO Box 123 Broadway NSW 2007 Australia.

Tel: +61 29514 4964. Fax: +6129514 4941.

Email: criedy@uts.edu.au

\section{Abstract}

\section{Purpose}

This paper draws on research undertaken for the State of Play in the Futures Field (SoPiFF)project to explore the contribution of futures work to understanding and resolving aspects of the global problematique and to examine the social interests evident in futures work. ${ }^{1}$

\section{Design/methodology/approach}

The project used an Integral meta-scanning framework to review publicly available futures material. The framework categorises futures work according to organisational type, social interests, methods, domains and geographic location. ${ }^{2}$

\section{Findings}

The futures field has made a series of significant contributions to understanding the global problematique and has contributed to the pre-conditions for its resolution. However, the bulk of mainstream futures work does little to improve the preparedness of humanity for looming future crises. More innovative futures work remains marginalised and largely ignored by the powerful and the wider public. There is a strong case for more effective political engagement than has occurred hitherto. 


\section{Research limitations/implications}

Further research is needed on shared definitions for the field, interactions with the media, public and other fields of enquiry and action, measurement of individual foresight capacity, strategies for achieving influence - particularly in the political sphere, the role of subcultures within the futures field and suitable publishing strategies.

\section{Practical implications}

The paper recommends specific actions to promote and publicise good work, provide annual digests of futures-related information, develop and use focused briefings, provide support for 'cutting-edge' futures work, further develop advanced futures methods, create new alliances, build the social capacity for foresight and strengthen the nexus between foresight and philanthropy.

\section{Originality/value}

The paper uses an Integral meta-scanning framework to provide a novel analysis of the futures field. The findings will be of value to all futures and foresight practitioners that are interested in the future success of the field.

\section{Keywords}

State of Play in the Futures Field; global problematique; social interests.

\section{Paper type}

Viewpoint

\section{Introduction}

The State of Play in the Futures Field (SoPiFF)project was an international review of futures literature, funded by the Foundation for the Future. It sprang from two sources. One was a comment by Walter Kistler that "humanity is like a vehicle going down a steep slope without a steering wheel, without brakes, and without a driver.” (Kistler, 2006) The other was a paper that posed the question "has futurism failed?" (Rejeski and Olson, 2006) Given the way that concerns about the global environment, global warming and "peak oil” to name but three items on a yet more crowded agenda, it seemed worthwhile to attempt to review the progress or otherwise futures-related work. Moreover, the present work should be regarded as a first iteration only. Subsequent surveys will not only benefit from critique of the current work but also review methodology and extend overall coverage.

The review was supplemented by a small number of interviews with futurists to clarify particular issues. The project used an Integral meta-scanning framework to review publicly available futures material. The Integral meta-scanning framework is described in detail by Ramos (2004) and Slaughter (2009b). The framework categorises futures work according to organisational type, social interests, methods, domains and geographic location. The review material is accessible at http://www.thinkingfutures.net/sopiff. 
Slaughter (2009b) describes the methods used for the (SoPiFF)project, the quantitative results, and the patterns and themes that emerged from the review. In this paper, we go beyond the quantitative analysis to develop a more qualitative understanding of the results and their relevance to futurists and foresight practitioners. In general, we are interested in understanding whether futures work is successfully preparing humanity to cope with a manifestly challenging future outlook and how it might become more successful.

Specifically, we consider the following questions:

1. What contribution has the field made to understanding and resolving aspects of the global problematique?

2. On balance is futures and foresight work progressive... or has it been captured by existing social interests? That is, does it merely help to further inscribe 'the way things are' or does it help to promote constructive change informed by a clear understanding of future challenges?

These questions are addressed in turn and followed by recommendations for further research and for practical actions that futurists and foresight practitioners may wish totake to expand and deepen the contribution of the futures field.

\section{Futures studies and domains of the problematique}

The term 'global problematique' (GP) was coined by the Club of Rome (CoR) in the 1970s and is associated with the publication of its first report Limits to Growth (Club of Rome, 2008; Meadows et al., 1972). It refers to an interlocking set of major systemic problems that were seen to be emerging at the time and have continued to do so ever since. In the CoR formulation the main categories are:

- Environment

- Demography

- Development

- Values

- Governance

- Work

- Information society

- New technologies

- Education

- Global society

- World economic and financial order.

Each of these topics has generated what might be called its own 'futures of -' industry, i.e., groups of scholars, practitioners, university centres and publications focusing on specific elements of the global problematique. Such work is by no means without value. 
However, what strikes one forcefully about the GP is that it simply cannot be approached through conventional topics, disciplines or subjects considered in isolation. It embraces a vast number of interrelated themes across the entire range of human knowledge and social development. No single subject, framework or perspective can encompass this enormous breadth, let alone encompass the depth and sophistication of thinking implied.

In response, some progressive thinkers and practitioners have called for, and begun to develop, multi- and trans-disciplinary frameworks that can integrate knowledge across disciplines and fields (e.g. Max-Neef, 2005; Pohl, 2008; Thompson Klein et al., 2000). Futurists have made important contributions to the development of these transdisciplinary frameworks (e.g. Lawrence and Després, 2004; Robinson, 2008; Russell et al., 2008; Wickson et al., 2006). Indeed, futures studies has increasingly taken on the aspect of a 'trans-disciplinary matrix' as it has developed.

Trans-disciplinary futures or foresight work is by no means the only way to approach the complex web of topics that makes up the global problematique - systems science, sustainability science, political science, ecology and depth psychology all have a role to play - but, in its more advanced forms, futures work is undoubtedly a leading contender. In fact, properly understood, advanced futures work may be an ideal way to approach and integrate complexity from many fields. This is, in fact, the intent of Integral Methodological Pluralism, or IMP for short, which is a natural extension of Integral Futures per se (Wilber, 2005). ${ }^{3}$

Despite the claims of futures work as an integrating framework for addressing the GP, web searches reveal countless other organisations, projects and initiatives that, in one way or another, seek to contribute to dealing with one aspect or another of the GP. While they have similar concerns and cover similar territory to futures and foresight work, they are grounded in different disciplines and in most cases 'the future' is a 'default topic' rather than a substantive one.

A notable example is provided by Will Steffen and his co-authors in 'Global Change and the Earth System - a Planet Under Pressure (Steffen et al., 2004). The book is based on what might be called an 'advanced scientific and systems paradigm' and it provides a coherent overview of available research about the past, present and likely future of planet Earth. It reconstructs the pre-human 'natural' functioning of the Earth system, the effects of current human impacts (termed 'anthropogenic forcing') and the likely ways these will play out under various future assumptions. This is such a wide-ranging, useful and authoritative book that its underlying narrative might be termed 'the story that connects'. As such it is a valuable source that can inform a wide range of people and initiatives. While it is not primarily a work of futures thinking and is not grounded in the futures literature it contributes substantively to a deeper understanding of the GP. Moreover, it is one of a growing number of high quality and insightful works that, taken together, not only augment the futures literature but in some respects redefine it and go beyond it (e.g. Esbjorn-Hargens and Zimmerman, 2009; McIntosh, 2008). Could this be an indication that the futures field as such is, in some respects, being superseded? To help answer this 
question we need to ask another: what does futures work contribute that may be considered unique?

\section{What does futures work contribute?}

Beyond providing a vital trans-disciplinary framework, there are several significant ways that futures-related work contributes to understanding the GP, and perhaps fewer that markedly contribute to resolving it. This section explores some of the reasons for this apparently ambiguous view.

The most significant contribution to understanding and resolving the GP is arguably found within a realm that receives surprisingly little attention from educators, futurists or, indeed, anyone else - the language and concepts of futures studies. These symbolic starting points are the sine qua non of almost any worthwhile futures activity. Simple futures concepts and tools stand at the very beginning of futures literacy and all the human and organisational capabilities that arise from this. Their particular contribution is that they endow the futures domain - the 'not here' and the 'not yet' - with human and cultural significance. That is, they allow people to begin to grasp the essential features of the human predicament and, over time, and with the agency of committed individuals, organisations and so on generate the futures literature, itself a precursor to real-world responses such as social innovations (Slaughter and Bussey, 2006).

Taken together, this body of work represents the product of many thousands of 'person years' and hence the distilled wisdom of those who have thought longest and hardest about the plight of humanity and its world. What has not been stated clearly or promulgated successfully is that within that literature are prefigured most, if not all, of the long-term solutions to the GP. A careful reading of this material shows very clearly how humanity arrived at its present predicament and what factors in society, human values, economic systems, technologies and so on led to the 'overshoot and collapse' trajectory. It also maps in considerable detail many of the 'escape routes' from this selfinitiated trap.

A leading example has already been mentioned - the thirty year research project carried out by the Meadows team, culminating in their 2004 book Limits to Growth - 30 Year Update (Meadows et al., 2004). To gain a flavour of this work and clarify its role it is worth taking note of some of the specific measures they proposed to help humanity avoid an overshoot and collapse future. They include the following:

- growth in population and capital must be slowed ... by human decisions enacted in anticipation of future problems rather than from feedback from external limits that have already been exceeded;

- throughputs of energy and raw materials must be reduced by drastically increasing the efficiency of capital ... In other words the ecological footprint must be reduced;

- sources and sinks must be improved and reactions speeded up; society must look further ahead and base current actions on long-term costs and benefits, and 
- erosion must be prevented and, where it already exists, slowed and reversed (Meadows et al., 2004, pp. 178-179).

What is immediately obvious from this list of proposed actions is that, in the absence of significant 'global shocks' none of them have been widely adopted, nor is it likely that they will be in the near future. This indicates that the widespread and systemic failure to respond to clear and consistent diagnoses of the GP and associated warnings and recommendations does not originate within the ambit of futures work but, rather, within the social, political and psychological contexts that futurists attempt to address. Here we should note that, currently, it is in relation to just these domains that mainstream futures studies is arguably at its weakest. Equally, however, futurists cannot be expected to bear full responsibility for the wider social failure to heed well-grounded analyses and their associated recommendations. From one viewpoint his can be read as a failure of leadership and politics at the very highest levels and a failure of social movements to bring sufficient political pressure to bear. From a different viewpoint it should be recognised that questions about future directions and the future shape(s) of societies have long been among the most difficult and contested areas of enquiry. Hence in politics, culture and religion, for example, such topics have remained controversial and resisted simple resolution.

Beyond the literature, futurists of all persuasions have carried out very many different types of research projects to elucidate different aspects of the GP. The SoPiFFresearch project identified some promising developments in the methods and scope of these projects (Slaughter, 2009b). First, there has been a clear shift from futures work relying on linear extrapolation to futures work that employs systemic modelling. While this development is not without its critics, it has supported a significant gain in the overall 'reach' and sophistication of futures research and plentiful evidence of this can be found in the main futures journals. Second, SoPiFFfound evidence of growing attention to cultural and humanistic domains, which is beginning to break down the fascination with purely technological and systemic futures. Finally, interior and exterior, and individual and collective views have been integrated within the currently developing Integral futures perspective. Thus, despite a 'generational gap', a process of renewal can perhaps be observed that holds out hope for the continued development and application of the field. ${ }^{4}$

Here it is helpful to distinguish between applied and theoretical research, even though the distinction is somewhat artificial. The futures journals tend, on the whole, to showcase the former. But the latter can also be found in, for example, Futures, Foresight and the Journal of Futures Studies. As noted, theorising in the field has received a significant boost and move toward much greater clarity and functional capacity through its use of Wilber's four quadrant model and the Integral Operating System (IOS) (Slaughter, 2008). A small but significant number of PhDs have been, and are being, written that serve to extend and enrich the knowledge base of the field. For example, Peter Hayward has explored the connections between individual and social foresight (Hayward, 2008). Jay Gary has 'filled in some of the gaps' by showing how 'middle level' theory in FS connects detailed work on the one hand with grand theories on the other (Gary, 2007). He has also evaluated a measure of foresight capability (Gary, 2008). Finally, one of the 
authors used an Integral futures framework to generate new perspectives on sustainable development and climate change response (Riedy, 2007). In time such work may help to establish the foundations of a more sophisticated and capable futures tradition that uses the new insights provided by adopting an Integral perspective to make a stronger contribution to resolution of the global problematique. More than most fields, the futures field seems open to furthertesting of the Integral framework in practice.

Another way that futures work contributes is through the few - but significant - school and university programs (and supporting literature) that have helped to resource different - but thus-far mainly Western - societies for the demanding tasks ahead. While the number of full-fledged programs at any level remains small, there is clear and pervasive evidence of a widespread pattern of innovations based on the efforts of many different people (Hicks and Slaughter, 1998). As noted above the world system continues to generate more powerful 'signals of change', signals that become increasingly difficult to ignore. It follows that such innovations and developments appear likely to receive greater support from various constituencies: parents, students, teachers, professional associations, community groups and so on. If and when a 'tipping point' is finally reached such that futures perspectives permeate education at every level, then we may see major shifts in social perceptions, readiness to contemplate structural changes and a rapid take-up of social and other innovations that have hitherto been marginalised. Achieving more rapid progress toward this stage therefore becomes a top priority.

A final contribution of futures work that is worth noting is its ability to open up spaces for creativity and innovation. A focus on the future allows present restrictions and barriers to be loosened, providing room for creative speculation about what is possible and how it can be achieved. Work that lacks a futures focus is in danger of taking the present circumstances as given, preventing access to a range of more innovative solutions. The value of this wider view should not be underestimated.

\section{Understanding the problematique is not the same as resolving it}

The above paints a positive picture of the contribution of futures work, particularly its aspirationsto understand the sources of the global problematique. The main drawback is that understanding the global predicament is by no means the same as resolving it. A clear-eyed view of the global system is difficult enough to attain in the first place and identifying some of the many and various steps toward it certainly do not mean that an overshoot and collapse future can be avoided. Indeed, an assessment of the unsustainable trajectory of human civilisation and the lack of progress to date of efforts to alter that trajectory suggests that the time to prevent some crises and collapses now lies in the past. Human lives and valued ecosystems appear set to be lost before human civilisation learns how to move onto a sustainable trajectory. What remains unclear is the extent of these inevitable crises and collapses and how much it will be possible to ameliorate or reduce their impact when they occur. 
Of course, crises present opportunities for renewal (Homer-Dixon, 2006). This has been apparent during the recent Global Financial Crisis, which has seen significant and rapid shifts in economic policy and large sums of money allocated to sustainability initiatives in economic stimulus packages. It is not unreasonable to conclude that the crises that lie ahead may constitute the 'social learning experiences' that will eventually help to create the demand for broad-based social foresight. To accept this, however, means that those working in futures-related occupations will need to re-focus their thinking and their work. To understand why, consider the following from Edward O. Wilson:

We have entered the Century of the Environment, in which the immediate future is usefully conceived as a bottleneck. Science and technology, combined with a lack of self-understanding and a Paleolithic obstinacy, brought us to where we are today. Now science and technology, combined with foresight and moral courage, must see us through the bottleneck and out (Wilson, 2002).

Apart from its brevity, what is impressive about this piece is the way it moves beyond more commonplace preoccupation with externals and correctly identifies the centrality of 'foresight and moral courage'. This is a real achievement. It is then but a small step to note that, for science and technology to be truly useful in this context, it will have to be framed in terms that foreground and embody these qualities. ${ }^{5}$ As Beck and others have pointed out, however, this remains a goal that is very far from current practice. Beck notes, for example, that the modernisation process, within which technology plays such a significant role, has led to what he terms a global "risk society." Furthermore, he adds, "risk society is not an option which could be chosen or rejected in the course of political debate. It arises through the automatic operation of autonomous modernisation processes which are blind and deaf to consequences and dangers.” (Beck, 1999) This adds a salutary note for futurists and foresight practitioners who often tend to overlook this kind of analysis.

However, the most significantconcept for this discussion is that of a future 'bottleneck', where options are foreclosed by looming crises and collapses. As Wilson sees it, things are going to get worse before they get better. The implication is that alternative futures are being foreclosed as we continue on an unsustainable trajectory and approach the bottleneck. For futurists that are used to thinking of the future as a realm of boundless possibilities, the idea of a bottleneck future constitutes a challenging paradigm shift. In this view, the task, for futures work, is to prepare for an extremely demanding period of human history and to help bring as many people and ecosystems as possible through the bottleneck, using 'foresight and moral courage'.

The notion of the immediate future as a 'bottleneck' and the perception of difficult and demanding times ahead is, however, not necessarily depressing, nor evidence for what is known as 'gloom and doom' pessimism. Rather, close attention to the forward view (or rather, a number of them, critically compared) also leads to the idea of our species facing a 'civilisational challenge'. The differences between this and more disempowering views are profound. The 'gloom and doom' view basically employs simple stereotypes to avoid thinking deeply and purposefully at all. It is here that we find the common strategies of 
denial, avoidance and repression not only in widespread use but also actively encouraged by a range of diversionary mass media oriented toward short term commercial and materialistic values. But to see the near-term future as a challenge that all societies need to rise towards engages different energies, opening up a broad panorama of possible responses. The idea underlying this very different perspective is, in fact, one small element of the elementary conceptual and tool base of futures work known as 'the empowerment principle'.

The fact remains, however, that the path to 'overshoot and collapse' has been visible for many years. In 1971, a year before the original Limits to Growth study, Italian writer Roberto Vacca published The Coming Dark Age. In this work he foreshadowed the likelihood of multiple breakdowns in the over-complex systems upon which civilisation depends of which we are now much more keenly aware (Vacca, 1971). There is a direct and continuous line between that book and others published more than 30 years later by writers such as James Kunstler and Morris Berman (Berman, 2006; Kunstler, 2005). Such writers present overlapping accounts of the decay of the great development project promoted by the West based on optimism, growth, exploitation of natural resources, rapid technological innovation and globalisation. If we take this evolving account seriously it becomes increasingly clearthat many of the key drivers of unsustainable growth and development are found within various worldview assumptions and their associated myths. For example:

- the view that 'growth is good'

- the view that fossil energy sources can sustain material growth

- the myth of the market as supreme arbiter of economic activity

- the idea that humans are masters of nature

- the view that the natural world is infinitely resilient

- the view that technology is a neutral tool that, on balance, leads to human betterment, and

- the view that the Western way of life is necessarily superior to all others. ${ }^{7}$

The key question that confronts us here, therefore, is the extent to which futurists and foresight practitioners have taken these ideas, myths and underlying assumptions pretty much as read and operated accordingly, that is, within the existing worldview, political structures and uneven distribution of power and, by contrast, the extent to which they have, like workers in many other disciplines, consciously regarded the above as contested issues that are both open to reinterpretation and central to everything that they do. To put it another way, is futures work on the whole narrowing or widening the bottleneck through which we need to pass. This leads us to a little studied aspect of futures work the role of fundamental social interests.

\section{Social interests in foresight work}

The SOPIFF project categorised the social interests driving futures material as 'pragmatic' (carrying out today’s business, but perhaps doing it better), 'progressive' (going beyond today's practices to invent and encourage new ways of doing things), and 
'civilisational' (looking beyond what currently exists and consciously working to create the foundations of the next level of world civilisation and culture) (Slaughter, 2009b). The point of so doing is reasonably obvious. Pragmatic work arguably has intrinsic limitations when confronted with what I've termed the "challenge to civilisation." Progressive work as defined above may well be considered more useful in that context but not necessarily within all environments. Finally, work motivated by broad scale and long term questions that address the viability of human life within an increasingly compromised world would appear to be a 'big ask' for organisations not specifically focused on such concerns. Within the sample of scans carried out for the SOPIFF project, the following results were found:
- Pragmatic
172
- Progressive
128
- Civilisational
39.

What these figures suggest is that the field may be dominated by pragmatic motivations. That is, the attempt to assist present systems, structures, organisations and so on to carry out their existing work but to do it more effectively (in other words, to make more money, to expand, to succeed in the current competitive market place). Pragmatic work, by definition, is unlikely to assist humanity to revise its underlying worldview assumptions or adapt to a fundamentally compromised world for one simple reason - it embodies other purposes and simply does not address those concerns. In fact it is both blind to, and in denial of, them. It represents what has been called 'the weight of the past' and largely ignores 'the pull of the future'.

Pragmatic work does too little to include alternative views, is dominated by 'technofutures' and primarily serves the interests of the state, defined to include both government and corporate interests. This does not mean that it lacks value. Pragmatic science and technology foresight is now a well- established approach that has real influence on public policy and supports better decisions about the development and deployment of technology. However, the scope of such work is narrow and it does not address civilisational challenges in any detail.

While pragmatic work is dominant, progressive work is also reasonably common and pursued by a substantial minority of practitioners and organisations. Such work looks for more than incremental improvements in current business. It both looks for new business and new ways of doing business: for example, through carbon credits, dematerialisation, the installation of mass solar energy systems, and so on. The best science and technology foresight work falls into this category. Viewed optimistically, work of this kind sees the future more as opportunity than threat and is instrumental in nurturing appropriate innovations and exploring new options across the board. Seen in a more sceptical light, however, it may be less influential than we might like to think. For example Dennis Morgan writes that: "progressive images of the future are still tied to the modern paradigm, which is defined by the world capitalist system and the idea of endless progress through scientific and technological developments” (Morgan, 2007). 
Finally, civilisational work is longer term and a good deal more speculative and ambitious. It looks beyond the current social and political order and considers the design, grounding and implementation of further 'layers' or 'stages' of civilised life (e.g. Raskin, 2006; Tonn, 2002). While deemed 'impractical' or 'utopian' by some it plays a vital role in creating 'mind spaces' for experimentation and the exploration of differentlystructured societies. When they are well articulated, such longer-term visions can provide inspiration and energy to open out possibilities that are often eclipsed by existing circumstances. Besides actual designs for future cities etc there are a number of works of speculative fiction that help to open out this domain for imaginative and intellectual exploration (Guin, 1986; Stapledon, 2003 [1930]). Civilisational work seems to be quite rare but it carries great promise because it frees up the mind and spirit for the longer-term journey into time that is arguably the destiny of the human species. We now turn to look at how these distinctions play out in different parts of the field.

\section{Social interests in the journals}

The view from the journals is ambiguous and suggests the need for a depth analysis beyond the present scope. ${ }^{8}$ Seven of eight leading futures journals were rated as progressive and six of these were also rated as also having a pragmatic, here and now, focus. Only one was judged to have a civilisational emphasis. What this suggests is that most of the journals stand at the perennial divide between these two categories. To push the interpretation somewhat, they could be said to 'straddle' these two different worlds, 'giving unto Caesar' in effect, 'that which is Caesar's' or, more colloquially, 'having it both ways'. Given the economic pressures that are driving commercial publishers to treat journals as 'mere product' this is unsurprising. It also serves to remind us that, currently, we do not have a mature journal that serves the field as a whole in ways that incorporate pragmatic, progressive and civilisational features. One journal that may achieve this is the Journal of Integral Theory and Practice, published by the Integral Institute. ${ }^{9}$

\section{Social interests and organisations}

There are four main futures organisations in the world and many more subsidiary ones. Of the main four, two are culturally conservative, one is ambiguously innovative and one is unambiguously innovative but currently in what might be called 'renewal mode'. As the associated scans show (see http://www.thinkingfutures.net/sopiff), the World Future Society (WFS) and the Millennium Project (MP), both based in Washington DC, are expressions of US thinking, resonant of US values and very much bound up with the preservation of a way of life that, by definition is unsustainable and cannot be preserved in anything like its current form. Both presume to be 'international', but the fact is that their agendas fit very comfortably within mainstream US interests. Neither has demonstrated a willingness or ability to understand and critique their own culture in any depth and therefore many of the more subtle 'drivers' remain out of sight and unregarded. In the past they've lacked the tools or self-understanding to engage with those aspects of Western / US culture that need to be revised and / or abandoned. However, the 
appearance in 2009 of the World Future Review, published by the World Future Society may herald a welcome change of focus. ${ }^{10}$.

The World Futures Studies Federation (WFSF) suffers from none of these problems since it is truly international, multi-cultural and critically enabled to its core. But the WFSF is itself in what appears to be a state of semi-permanent transition as the shifting landscapes of futures-related activity and of the current warp and weft of cultural identity and being around the world cause it to question its own identity and purpose. Its members constitute a widely scattered network of interacting critics, scholars, teachers, practitioners, social innovators and others who gain a great deal from knowing each other and meeting at conferences. But the many other governmental organisations and NGOs that cluster around futures-related concerns tend not to be involved in the WFSF or be at all interested in joining it. At the same time there's a clear growth of networked activity around the quasi-official developments in science and technology foresight. Indeed, this appears to be the main current growth area in the field. ${ }^{11}$

The Association of Professional Futurists (APF) is certainly the most vital and developing entity within this small group of futures organisations. It was initiated a few years back by a number of younger futurists, many of whom had trained either in the program run by Jim Dator at the University of Hawaii, or in the program led by Peter Bishop at the University of Houston, Clear Lake. The APF now has about two hundred members, mainly in the US, but also overseas. The organisation is still young and thus it is difficult to know how it will proceed. On the one hand there's a concern, perhaps, that the work of most of the APF pioneers is largely as consultants to US corporations, and this may limit the purview of the organisation. Set against that, however, is the fact that what may be the best book on foresight practice was edited by two of the APF's leading members (Hines and Bishop, 2006). This suggests that the APF may be a leading example of the successful fusion of pragmatic and progressive work.

The implication from this overview is that the main organisations of the field are not philosophically aligned and there is probably little prospect that they ever will be. One way out of this fragmentation trap is perhaps to turn to Integral shorthand and consider the injunction to 'transcend and include'. If this were done, and done effectively, then the current fractures and divisions could perhaps be healed.

\section{The contribution of futures work}

This paper started with two questions:

1. What contribution has the field made to understanding and resolving aspects of the global problematique?

2. On balance is futures and foresight work progressive ... or has it been captured by existing social interests? 
We can now attempt to answer both. In the former case, it is clear that the field has made a series of genuine contributions to understanding the GP. They include the steady evolution of futures concepts, tools and methods, the training of new generations of practitioners and the rise of futures organisations and the associated publications that comprise the futures literature. The 'yield' of this activity is a core of perhaps 200-300 substantial works that collectively contain an overlapping series of diagnoses of the human predicament as well as many constructive suggestions for dealing with it and finding more life-affirming ways forward. Many themes have emerged from this work, none more informative and agenda setting than that of the 'sustainable society'. An annually updated Annotated Futures Bibliography monitors this and related issues (Slaughter, 2009a).

As for helping the world move towards such a society, however, the story is obviously more complex. For the fact is that human beings and their societies and cultures do not exist on one developmental level, but many. They share a common world but do not, in any way, share a common civilisational worldview or paradigm. Very often what looks like 'a solution' from within one individual or group in a particular place looks very different elsewhere. Moreover, attempts by the currently powerful to impose a Western view of democracy, the desirability of markets and the viability of endless material growth, have manifestly failed. It is within this unstable, contested and frankly chaotic environment that futurists have, on the whole rather ineffectually, put forward their proposals for innovation and change. Mostly, they have been heard neither by opinion leaders, the powerful nor ordinary people at all. One must admit, therefore, that the field as a whole has thus far been unable to resolve key aspects of the GP.

It can legitimately be claimed, however, that what has been achieved has been the creation of some of the pre-conditions for such resolutions - pre-conditions that can and will become available as earlier ways of life cease to be viable and are overtaken by some of the external events that were briefly referred to above. At those times proposals for better governance, better ways of preserving and even enhancing the environment, more effective strategies of conflict resolution, greater clarity about the paths forward for human and social development - in fact a huge number of social and other innovations may be able to 'come in from the margins', as it were, and have their chance to be tested and implemented. We have observed this process recently in response to the Global Financial Crisis, where ideas such as 'green jobs' and a range of 'green innovations' have moved rapidly from the margins into mainstream economic policy.

Regarding the second question, it appears that the most technically accomplished futures work has largely been taken up by government entities and commercial enterprises and applied to the limited pragmatic needs of the day. This must be counted as a qualified success since futures thinking is increasingly seen as a necessary part of government and commercial decision-making. The most significant growth in the field, therefore, is not in areas where educators, social innovators, idealists or radical thinkers are found but with state and regional foresight projects. Most futures and foresight work appears to be undertaken for governments and corporations, usually by practitioners from other fields who lack an explicit grounding in the futures domain. Relatively few are yet employed in 
the 'third' or social sector - though this may be changing. There are small pockets of innovative groups that carry out outstanding work from time to time. The Great Transition initiative is an example of this (Raskin et al., 2002). There are considerable numbers of innovative individuals who are willing and able to think outside conventional constraints. We also noted a new or renewed tradition of futures work that is fully cognisant of human and cultural 'interiors'. At this time, however, these more progressive forces, capacities and tendencies remain underdeveloped and in no way compensate for the bulk of conventional work carried out within mainstream environments. The most innovative futures work therefore remains marginalised and largely ignored by the powerful as well as by the media-entranced masses.

The challenge now is how to take the enormous potential of advanced and applied futures and foresight work and take it to its next stage of implementation. How might this be accomplished? To answer this question we need to briefly review the present state of the world.

\section{Futures work and the 'state of the world'}

During the early decades of its development what some have termed the futures field possessed a number of core characteristics. Among these was an essential and almost utopian optimism about the capacity of human beings and societies to influence their future and, closely linked with this, a core notion of 'alternative futures'. The latter suggested that if the right decisions were made then societies could 'navigate' away from disastrous futures toward those more in harmony with human desires. That is, futures characterised by peace, equity, justice, environmental sustainability and so on. Yet by the late 1990s these assumptions had become problematic. In a paper published in early 2000, one of the authors suggested that:

The year 2,000 and the shift to a new century and millennium have attracted many hopes for improvement in the human condition. But most of these hopes will not be sustained, at least not yet. The diet of 'bad news' that characterised the late 20th century will continue for a long time to come because humanity is only part-way through a transition that will take many, many years to complete (Slaughter, 2000, p. 43).

In the years since then, there have been limited and local successes but these have not been sufficient to alter the trajectory of human civilisation and we are left to confront an ever more disastrous outlook for the human race. Specifically, the 'inconvenient truth' noted by Al Gore and others, has, in a few short years, steadily turned into something much more fundamental and profoundly threatening. In Gore's terms that 'truth' concerned the steady rise of environmental indicators suggesting that global warming was going to be the make or break issue for us all. What Gore did not say, however, was that the issue was actually founded on another - that humanity had already outgrown the inherent limitations of its world. So it makes more sense to see global warming as itself a key indicator (and by no means the only one) of humanity's refusal to acknowledge that 
it has expanded to its current size and state of development mainly by converting and degrading or destroying natural systems. Civilisation has appeared to thrive in large part because it has succeeded in deferring the costs of this process into the ever-receding future. Except that, at some point, the future becomes now. And that is where we are today.

At first sight this may seem paradoxical. After all, the processes of global degradation have been understood for several decades and described in ever-greater detail. And yet they cut no ice with all but a globally insignificant minority. Most people in most places around the world, both rich and poor, are focused on their family, their job, their children and, perhaps, their immediate environment. The future is distant - 'another country' - or it was. Now that deferred costs across the board are starting to disrupt our here-and-now lives we are collectively confronted by the consequences of human limitations.

How have futurists responded to this deterioration in the global outlook? We noted above how some have attempted to diagnose and suggest ways forward. It remains a fact, however, that much of the best written material no longer originates from a specifically futures context. For example, some of the most useful books from recent times are written by 'intelligent generalists' who've read the signals for themselves, interpreted their meanings and produced works of great insight and power (Kunstler, 2005; Steffen et al., 2004). Just as, on a larger scale, humanity remains divided and apparently incapable of cooperating sufficiently to rein in the tide of overdevelopment and destruction so, too, the futures field exhibits these very same deficiencies.

The broad refusal of active agents within the field to seek out, encourage and welcome critique is arguably another of the reasons that its progress to a more mature stage of development and capability has been impeded. Equally there are still many actors that cling on to idealistic notions of history and an undiminished belief in the ability of human agency to determine historical outcomes. Work that demonstrates this level of naivety helps to explain why the futures field remains marginalised in some environments. Few with any real historical understanding will welcome a field characterised by naivety and tribal dissonance. In rejecting it they will dispense with the proverbial baby as well.

The time is overdue for the futures enterprise (however conceptualised) to acknowledge that some of its early assumptions and practices have become problematic. Among these is the assumption that human beings have the capacity to determine or control history. Half a century ago, American philosopher Ronald Niebuhr suggested that 'the whole drama of history is enacted in a frame of meaning too large for human comprehension or management' (Niebuhr, 2008 [1952], p. 91). Whether or not this is true, there is no doubt that any individual piece of futures work, or even the futures field as a whole, cannot hope to substantially influence the flow of events without engaging with issues of politics, power and the role of competing worldviews and interests. Resistance from powerful interests to the remedies proposes by futurists make real influence difficult to achieve. 
Take, for example, the failure of the United Nations to prevent or manage conflicts. While many have understandably invested much hope in this organisation, its founding flaws are among the reasons it has been largely ineffective. The fact that five countries of nearly two hundred have a veto capacity within the Security Council means that it cannot act democratically or independently. Futurists and foresight practitioners may be able to imagine alternative systems of world government that could be viable in the future, yet if anysuch system threatens the interests of those five countries it has no serious prospect of adoption. It is difficult to avoid the conclusion that current, largely ineffectual, arrangements serve existing dominant nations rather effectively when those interests are considered in isolation and in the short-term. Clearly, however, they serve them badly when placed in the global context outlined here and considered in the long-term. The shift from 'short-term' to 'longer-term' is way overdue.

There is every reason to believe, then, that humanity is headed for a 'perfect storm' comprised of:

- global warming and sea level rise,

- peak oil and its aftermath,

- regional environmental collapse,

- economic and financial instability, and

- social upheavals and migrations on a scale never seen before (Dyer, 2008).

Despite decades of warnings the window of opportunity to respond to these issues proactively, rather than through crisis management, is rapidly closing. As a result, human civilisation has reached the point when its ability to act independently within the global system is about to be curtailed. It is now too late to regret the fact that the 'writing on the wall', the many 'signals of change' have been 'delayed, denied or ignored'. Instead, we appear constrained to operatewithin the current context to find ways to increase the effectiveness of futures work in responding to and reducing the impact of looming crises. It is appropriate, then, to turn to recommendations.

\section{Recommendations}

Two broad sets of recommendations have emerged from the SOPIFF study. One deals with questions for further research. The other deals with specific actions. Both can and should be critiqued, supplemented and extended. The question, however, of what agencies might take them up is left open for the time being. The following are not listed in any particular order of importance. 


\section{Questions for further research and actions to be undertaken}

* Defining the field. Questions about defining a futurist, a foresight practitioner and the futures field are commonly mentioned. If there are ambiguities for those involved, then it clearly becomes much more difficult for the 'person in the street' to grasp what all this activity is about. More commonly shared definitions are urgently required.

* Media presence. The lack of any well-defined media presence for futures work has been noted. How the field should be presented and who, indeed, would be able to speak for more than a fragment of it, are key questions. An over-arching media strategy needs to be developed.

* Public knowledge base. A substantive knowledge base for entrée to the field has been in use for more than a decade. But there is currently no such introduction available to raise the public profile of the field. The nature, content and focus of an introductory knowledge base need to be developed, rendered into effective forms (using old and new media) and put to far wider use.

Measuring foresight capability. Many - perhaps most - decision makers encounter internal 'moral impediments' when it comes to understanding and adjudicating futuresrelated policies and decisions. Rather than leave this implicit it would be helpful to have an objective instrument to measure and assess an individual's 'foresightedness' and to use this as an explicit criterion to assess the suitability of candidates for senior appointments. The work of Hayward and Gary both contribute to this (Gary, 2008; Hayward, 2008).

* Assessing case studies. Case studies play a vital part in establishing how well (or badly) any field of human activity is faring. This is clearly true of the futures domain. There is, however, currently no widely accepted framework or methodology for assessment. While these can arguably be derived from the Integral metascanning approach, more detailed work of this kind has yet to be carried out and validated. Recent work by the European Foresight Monitoring Network is a step towards this (Butter et al., 2008).

* Resolving the 'influence / power' dilemma. A central conclusion to have emerged clearly from the study is that a great deal of futures work does not achieve significant influence because it takes place outside of the arenas of social decision-making and power and, moreover, is often couched in language that may not be readily comprehensible. Yet to achieve influence it is often the case that such work becomes incorporated into existing state and corporate systems, thus negating what is most 
original and / or challenging about it. Research on how futurists navigate this dilemma in practice would make a valuable contribution to the field and provide a foundation for identifying new strategies for achieving influence.

*Schools of thought in futures work. Drawing on the SoPiFFproject, Morgan identifies eight schools of futures thought (Morgan, 2009). They are suggestive but by no means the last word on this subject. A good deal more systematic and comparative work is required to shed more light on exactly what the divisions and distinctions are and, equally, what they portend for the future of the field itself. Currently the most promising framework available is arguably that provided by the Integral method. Implications include resolving questions about how divided the field really is and what the prospects may be for more unified approaches to major questions facing humankind.

* Futures and foresight in relation to other fields of enquiry and action. If the question of defining futures work is serious, then of equal or greater concern is the problematic relation of the domain with others that are closely related, such as leadership and strategy, organisational development, public policy and so on. Is it possible to develop some sort of 'meta map' of these interactions? To what extent does an Integral overview fulfil this need, or will the latter be perceived as yet another 'school' or, worse, a new 'totalising framework’?

* Role of social innovation and innovators. This question follows on from the one above. Social innovations can be taken to be a separate domain and yet they are also one of the key outputs of successful futures work. To what extent does the 'tool kit' of social innovators (for example, creative thinking, negotiation skills, conflict resolution etc) intersect with that of futures work?

\section{?}

* Contributing to sustainability. One of the central themes of the research program is that of sustainability. Yet currently there is little or no material available that attempts to summarise or evaluate how such work supports and assists sustainability initiatives. An appropriate body such as a university department should be charged with making such an assessment and making the results widely known. Riedy's contribution to this project outlines progress thus far (Riedy, 2009).

* Publishing. As noted in the relevant section, the field is quite poorly served by the existing spread of journals. Currently, none of them is broad and balanced in the sense adopted by the metascanning framework. Equally, none is truly international and multicultural, despite claims to the contrary. There is clearly a need not for more journals but, rather, for what might be called a 'summarising and integrating capability' that spans the domains outlined here. 
Independent book publishing by specifically futures-oriented organisations is weak. The Foundation for the Future publishes the outputs of its own invitational events. The WFSF has published a number of high quality but otherwise difficult-to-obtain conference volumes. The WFS publishes conference readers that are markedly banal and add little of substance to the field. Some of the most consistently useful books are the annual State of the World and Vital Signs volumes published by the World Watch Institute. Overall, the most innovative and useful writing is put out through a variety of independent niche publishers such as the now defunct Adamantine Press (London), Transaction Press (New York), Berrett-Koehler (San Francisco) and Earthscan (London).

The positive side of this picture is that the diversity of such independent publishing may be healthy for the field as a whole, allowing 'a thousand flowers to bloom' in a variety of places. The drawback is that the initiative lies not with any agency within the field but in the hands of those for whom commercial imperatives are the primary concern. Hence for books to be published requires a market-oriented justification, not one based on the needs of people, societies and global wellbeing. Possibly the only entities that can move beyond these limitations are university departments and philanthropic foundations. There is a vital nexus here that is summarised below and that requires sustained attention.

* Promoting and publicising 'good work.' A number of examples of outstanding work have been recognised in the SOPIFF project. They include:

- the 'great transition’ initiative (Stockholm Environment Institute);

- the Institute for Futures Studies (Sweden);

- work on medical futures by the Institute for Alternative Futures (Washington);

- work on social foresight at the Australian Foresight Institute (Melbourne), embodied in the Strategic Foresight Monograph series, available at http://www.swinburne.edu.au/business/research_reports.html\#2.

Parallel with these explicitly futures-focused initiatives are those carried out by other organisations working in related areas, for example:

- the International Panel on Climate Change (UN); and

- the World Social Forum (international).

The Foundation for the Future already recognises this principle in its annual awarding of the Kistler Prize for the best book on developments in science and technology and the APF recognises the Most Important Futures Works of the year and has initiated a Student Recognition Project to recognise student papers. Similar prizes could now be offered for other, related, categories. For example:

- the best published paper in a futures journal; 
- the best specifically futures-related book;

- the best published case study of applied Futures / foresight work.

Beyond this, a further means to focus more international attention on quality futures work would be an annual volume of Best Futures Writing, which could be launched through an agreement with a reputable publisher willing to publicise and promote the new series around the world.

* Annual digests. There are various futures-related scanning publications available in the world, many of them available via the Internet. Up to now the most well known was Future Survey which ceased publication in 2008. Another source is the on-line journal of the New Zealand Futures Trust, Future Times, called Future Watch. The latter is the work of one individual, Jennifer Coote, who carries out this service as an ethical commitment, not an income-bearing one. There are a growing number of 'horizon scanning' services that are available on-line mainly to subscribers. While those working in this area quite obviously do their best, the results are uneven and of variable quality. Thus, what is lacking is anything approaching a credible annual overview or digest of this material that could readily be accessed not only by specialists but also by the general public.

In summary, there is a need for two kinds of annually produced, critically evaluated, balanced and international digests. One would be for the general reader; the other would be for use in civic society organisations - specifically public sector organisations such as local government, school systems and third sector organisations such as churches, charities and foundations. The latter are particularly poorly served at present and represent a largely unexplored opportunity for the widespread understanding and use of futures-related knowledge.

* Focused briefings. A related option is to recognise that digests of global scanning material constitute only a first step. Strategies are required to add value to such material by, for example, up-grading it into useable briefing materials. That is, translating relevant information into the specific forms by which it can be acknowledged, understood and acted upon. One of the many ways it is useful to be 'integrally informed' is to be able to achieve just this kind of translation of difficult or challenging material into everyday terms. Similarly, the relevance of futures work to actual imperatives that are embodied in 'the State' such as security, system maintenance and legitimation is also vital. Futures work can only achieve real influence by translating its findings and recommendations into terms that either connect with existing state imperatives or contribute to the eventual transformation of state imperatives. The basic point is that successful futures work cannot, by definition take place only in conditions dictated by 'ivory tower' remoteness or commercial 'in confidence' limitations. 
* Support for 'cutting-edge' work. One of the clear conclusions to emerge from the SoPiFF study is that the vast majority of futures work is carried out in largely conventional ways. If we take as our focus the 'big picture' concern of how humanity will be enabled to 'escape from' its self-constructed trap, achieve a viable 'great transition', 'or successfully 'move through the bottleneck' of the near-term future, then it makes a great deal of sense to provide appropriate support for cutting edge work that operates in the most effective, progressive and advanced forms.

Within the terms of an integrally informed metascanning approach, this means seeking out and supporting high quality work that is credibly focused on civilisational futures. That is, individuals, groups and research centres that take as one of their central subjects disciplined and wide-ranging work on the foundations of the next civilisation: its worldview, values, infrastructure and the developmental capacities of its citizens and their organisations. This is a 'big picture' response to a 'big picture' problem.

* Further development of advanced methods. This study has noted the success of systems methods over the last couple of decades. It has also acknowledged the value, the increase in range, capability and quality of understanding that attends a view of the world as indeed a single complex interconnected system. It is also clear, however, that there are other methods that specifically address the human and cultural interiors that are based on a number of 'other ways of knowing'.

The Integral approach is one way to carry this agenda forward. It emphasises that conventional 'exterior' approaches to world issues only cover part of the territory. By drawing more fully on the 'interior collective' (society) and the 'interior individual' (the unique world of each person) domains the field can arguably attain a new level of maturity. Some of the consequences include:

- a balancing of inner and outer perspectives;

- multiple and yet systematic views of our species’ history and development;

- access to the dynamics of social construction, innovation and 'deep design';

- aspects of the 'deep structures' of this and more advanced civilisations;

- a new focus on the whole spectrum of developmental options for practitioners and others (not merely their cognitive abilities); and

- new and renewed methodologies and approaches (Slaughter, 2008, p. 123).

In summary, the integral approach allows us to avoid some of the traps and limitations of earlier methods; re-define the central purposes of futures work; provide a cultural diagnosis and a renewed story of the world; and, overall, help re-define the path ahead that humanity could choose to take. Uneven and modest levels of human and cultural development, allied with powerful technologies have been key drivers of the dynamic that leads to overshoot and collapse futures. In order to 'solve' the global probematique we have to look beyond the 'ways of knowing' and the 'ways of valuing' that created it in the first place. It makes sense, therefore, to explore ways of assisting those entities that 
are currently pioneering new methods and to subject their work to careful evaluation and assessment. A subsequent research program should be carefully constructed to carry out this vital task that, currently, is not being performed anywhere.

* Pursue greater political understanding and influence. Although one of the foremost centres of excellence in the 'futures' domain has been within the School of Political Science in the University of Manoa in Hawaii, ably led by Jim Dator, the political influence achieved by futurists and foresight practitioners appears to have been rather slight. Yet, as noted above, the emergence of global 'drivers' indicating the rise of serious global dysfunctions may provide new opportunities to seek out and make new connections between these and advanced futures work. While societies necessarily resist change for a number of good reasons, there are now multiple good reasons why the pursuit of sustainability provides a compelling mandate for change. Hence a basis for engaging in newly-formulated approaches to political activity may well be emerging. Some of these may involve a rapproachment with radical or 'green' groups and parties. Others could explore the implications of what Fry refers to as 're-directive practice' - a promising new approach to social and political innovation. (Fry, 2009)

* Build capability. A further weakness in the current scene is that very few projects appear to take seriously questions of social legitimation and capacity building. It is as if the implicit view is that futures work takes place in isolation and is 'delivered' to clients without much further thought. Futures work in private and governmental administrative interests are not uncommon. But futures work in the public interest remains rare.

In order to achieve wider legitimation, futures workers need to understand how central this issue is to the normal operation of any society. Currently, some very peculiar assumptions stand at the heart of the social order precisely because they received legitimation some years ago. For example, our attitude to, and uses of, oil have been formed within a culture of capitalist exploitation and an ethos of a very particular form of growth and social development. We now know that the society and world so created is completely unsustainable. In other words, worldview components that were once deemed legitimate are now clearly not so. They need to be replaced by others that are appropriate to the times.

Similarly, if futurists are interested in building the social capacity for futures thinking then they need a framework of understanding and action through which to implement it. One such is offered by the successor to the AFI program on social foresight. It can no doubt be improved. Other models can and should be offered. Currently, however, there is very little attention being given to this crucial matter. Hence support should be given to advanced futures work on these two areas:

- $\quad$ social legitimation and de-legitimation of cultural assumptions; and

- theories in action regarding the development of social foresight. 
It should be emphasised that these issues are not 'merely academic'. Rather, they stand at the very heart of the future viability of the futures enterprise and, by extension, that of future society as well.

* Strengthen the nexus between foresight and philanthropy. While not directly addressed in the project, foresight and philanthropy are both motivated by deeply felt impulses of care and concern for humanity. But it is normally the case that foresight is linked with pragmatic and / or bureaucratic purposes and philanthropy is uniformed by the insights arising from high quality foresight work. It is therefore vital for these two enterprises to begin working more closely together. In fact, there may be no more potent strategy available than to draw on the combined strengths of these hitherto-separate domains. Specific suggestions on how to achieve this are set out in Slaughter et al. (2004). One starting point would be to set up a working party comprised of individuals from each sector and to charge it with creating an agenda and related resources for an invitational conference.

\section{Conclusion}

The futures field has made a series of contributions to understanding the origins and nature of the global problematique. Further, it has helped to put in place some of the preconditions for its resolution. While problematic in some respects, what some have called 'the futures field' has been, and continues to be,a significant source of potential social innovations, proposals for better governance and other sustainability strategies that will be available for adoption when sufficient political will is mustered or in response to emerging crises.

However, the bulk of mainstream futures work does little to improve the preparedness of humanity for the latter. Equally, more advanced futures work remains marginalised and largely ignored by the powerful and the wider public. As the sustainability crisis continues to deepen, the futures field needs to respond to the narrowing of humanity's future options by finding ways to increase its relevance and influence. The paper recommends specific actions to promote and publicise good work, provide annual digests of futures-related information, develop and use focused briefings, provide support for 'cutting-edge' futures work, further develop advanced futures methods, pursue greater political understanding and influence, build the social capacity for foresight and strengthen the nexus between foresight and philanthropy.

More generally, futurists need to become critically reflective about the social interests that they are representing and whether their work contributes to a widening or narrowing of humanity's future options. The broad array of individuals and organisations that comprise the field is, in some ways, uniquely equipped to contribute to the resolution of the global problematique but it will continue to fall short of its collective potential unless it resolves some major issues that centre upon political power and competing worldviews 
and interests. The Integral framework that stands behind this project can assist by providing a coherent account of the human interior - the realm of values and worldviews. But a 'grand synthesis' that would finally answer the question posed by Rejeski and Olson in 2006 has yet to be achieved and rendered into practice.

\section{References}

Beck, U. (1999) World Risk Society, Polity Press, London.

Berman, M. (2006), Dark ages America: The final phase of empire, Norton, New York.

Butter, M., Brandes, F., Keenan, M. \& Popper, R. (2008), "Evaluating Foresight: an introduction to the European Foresight Monitoring Network", Foresight, Vol. 10 No. 6.

Club of Rome (2008), "Briefing Note: Mission and Activities of the Club of Rome", BN/08/4.1, Club of Rome, May 2008, http://www.clubofrome.org/eng/about/instant_information_docs/Briefing_NoteMission_and_Activities_of the_Club_of_Rome.pdf.

Dyer, G. (2008) Climate Wars, Scribe, Melbourne.

Esbjorn-Hargens, S. \& Zimmerman, M.E. (2009), Integral ecology: Uniting multiple perspectives on the natural world, Integral Books, Boston and London.

Fry, T. (2009) Design Futuring. Sustainability, Ethics and New Practice, University of New South Wales Press, Sydney.

Gary, J. (2007), Why futures studies needs a theory base, Unpublished manuscript.

Gary, J. (2008), Evaluation of the Dian scales as a foresight measure, PhD thesis, Regent University, VA, USA.

Guin, U.L. (1986), Always coming home, Bantam Books, New York.

Hayward, P. (2008), Developing wisdom: How foresight develops in individuals and groups, VDM Dr Muller, Saarbruken.

Hicks, D. \& Slaughter, R. (1998), Futures education: World Yearbook of Education 1998, Kogan Page, London.

Hines, A. \& Bishop, P. (2006), Thinking about the future: Guidelines for strategic foresight, Social Technologies, Washington.

Homer-Dixon, T. (2006), The upside of down: Catastrophe, creativity and the renewal of civilization, Island Press, Washington. 
Kunstler, J. (2005), The long emergency, Atlantic Books, London.

Kistler, W. (2006) Foundation for the Future: Review of Foundation Activities 19962006, p2, available at: http:www.futurefoundation.org

Lawrence, R.J. \& Després, C. (2004), "Introduction: Futures of Transdisciplinarity", Futures, Vol. 36 No. 4, pp. 397-405.

Max-Neef, M.A. (2005), "Foundations of transdisciplinarity", Ecological Economics, Vol. 53 No. 1, pp. 5-16.

McIntosh, A. (2008), Hell and high water: Climate change, hope and the human condition, Birlinn, Edinburgh.

Meadows, D.H., Meadows, D.L., Randers, J. \& Behrens, W.W. (1972), The Limits to Growth, Universe, New York.

Meadows, D.H., Randers, J. \& Meadows, D.L. (2004), Limits to growth: The 30-year update, Earthscan, London.

Morgan, D. (2007), "The global problematique and schools of futures thought", unpublished research document, SOPIFF project.

Morgan, D. (2009), "Futures schools of thought within the integral futures framework (Part I)", Foresight.

Niebuhr, R. (2008 [1952]), The irony of American history, Chicago University Press, Chicago.

Pohl, C. (2008), "From science to policy through transdisciplinary research", Environmental Science \& Policy, Vol. 11 No. 1, pp. 46-53.

Ramos, J.M. (2004), "Foresight Practice in Australia: A Meta-Scan of Practitioners and Organisations", Australian Foresight Institute.

Raskin, P., Banuri, T., Gallopin, G., Gutman, P., Hammond, A., Kates, R. \& Swart, R. (2002), "Great transition: The promise and lure of the times ahead", Stockholm Environment Institute, Boston.

Raskin, P.D. (2006), "The great transition today: A report from the future", GTI Paper Series: Frontiers of a Great Transition, Paper \# 2, Tellus Institute, Boston.

Rejeski, D. \& Olson, R.L. (2006) Has futurism failed? Wilson Quarterly, Wilson Institute, Washington D.C., Winter 2006, p 14-21.

Riedy, C. (2007), The Eye of the Storm: An Integral Perspective on Sustainable Development and Climate Change Response, VDM Verlag Dr. Muller, Saarbrucken, Germany. 
Riedy, C. (2009), "The influence of futures work on public policy and sustainability", Foresight.

Robinson, J. (2008), "Being undisciplined: Transgressions and intersections in academia and beyond", Futures, Vol. 40 No. 1, pp. 70-86.

Russell, A.W., Wickson, F. \& Carew, A.L. (2008), "Transdisciplinarity: Context, Contradictions and Capacity", Futures, Vol. 40 No. 5, pp. 460-472.

Slaughter, R. (2000), "A personal agenda for the 21st century", Futures, Vol. 32 pp. 4553.

Slaughter, R.A. (2008), "What difference does 'integral' make?", Futures, Vol. 40 No. 2, pp. 120-137.

Slaughter, R. (2009a), "Annotated futures bibliography", Foresight International, http://foresightinternational.com.au/catalogue/product_info.php?cPath=44\&products_id= 115.Slaughter, R.A. (2009b), "The State of Play in the Futures Field: An Introduction and Overview", Foresight.

Slaughter, R.A. \& Bussey, M. (2006), Futures thinking for social foresight, Tamkang University Press, Taipei.

Slaughter, R.A., Simone, S.D. \& Braidotti, D.G. (2004), "Foresight and philanthropy: Towards a new alliance", Monograph Series 2003-2006, No. 9, Strategic Foresight Program, Swinburne University.

Stapledon, O. (2003 [1930]), Last and first men, Gollancz, London.

Steffen, W., Sanderson, A., Tyson, P.D., Jager, J., Matson, P.A., III, B.M., Oldfield, F., Richardson, K., Schellnhuber, H.J., II, B.L.T. \& Wasson, R.J. (2004), Global change and the earth system: A planet under pressure, Springer Verlag, Heidelberg, Germany.

Thompson Klein, J., Grossenbacher-Mansuy, W., Haberli, R., Bill, A., Scholz, R.W. \& Welti, M. (eds) 2000, Transdisciplinarity: Joint problem solving among science, technology and society - An effective way for managing complexity, Birkhauser, Basel.

Tonn, B.E. (2002), "Distant futures and the environment", Futures, Vol. 34 No. 2, pp. 117-132.

Vacca, R. (1971), The coming dark age, Mondori Editori, Rome.

Wickson, F., Carew, A.L. \& Russell, A.W. (2006), "Transdisciplinary research: characteristics, quandaries and quality", Futures, Vol. 38 No. 9, pp. 1046-1059.

Wilber, K. (2005), "Introduction to the Integral Operating System", in R. Slaughter (ed.), The Knowledge Base of Futures Studies, Foresight International, Brisbane. 
Wilson, E.O. (2002), The future of life, Abacus, New York.

\section{Endnotes}

${ }^{1}$ The authors recognise that the terms 'futures field' and 'global problematique' both raise significant questions in their own right. In the former case it is acknowledged that the 'field' is a highly diverse and frequently unaligned group of individuals and organisations. Set against that view, however, are a number of shared elements that include key concepts, a core literature, an evolving 'knowledge base', a range of methodologies and high levels of interaction between some, but not all, practitioners. Equally, the term 'global problematique' can be taken to impose a false unity on a bewildering set of interlocking processes and problems or a way of approaching these at a high level of generality that recognises the complexity beneath.

${ }^{2}$ Details of the methodology are outlined in the accompanying introductory paper as well as on the web site created for the project.

${ }^{3}$ Integral Methodological Pluralism (IMP) is a subject in its own right and therefore original sources should be consulted. Briefly, however, it offers a framework that recognises interior and exterior perspectives on each of the quadrants in Wilber's four quadrant model. An attitude of watchful scepticism is entirely appropriate when considering IMP. However, a number of suggestive case studies on how IMP has been applied to a variety of fields can be found in the Journal of Integral Theory and Practice (JITP) published quarterly by the Integral Institute, Boulder, Colorado, USA.

${ }^{4}$ Further evidence of these developments can be found in the Australian Foresight Institute (AFI) monograph series on social foresight (2004-2006), which is available at http://www.swinburne.edu.au/business/research_reports.html\#2.

${ }^{5}$ The view that technology is not neutral is now widely accepted. It follows that advanced applications will reflect inherent social and political values. Hence, in the US, for example, the military applications of, say, nanotechnology, are certain to be widely explored will in advance of any applications for social well-being. This means that dystopian futures become much more likely.

${ }^{6}$ The empowerment principle has been rendered into a simple workshop exercise (Slaughter and Bussey, 2006, pp. 119-123).

${ }^{7}$ Worldview issues and concerns are central to the tradition of 'critical futures studies' and can be seen as forerunner to the Integral tradition, now taking shape.

${ }^{8}$ Eight leading futures journals were included in the survey: Future Times (New Zealand); the Journal of Futures Studies (Taiwan); Futures Research Quarterly (USA): Future Survey (USA); Futures (UK); Foresight (UK); Technological Forecasting and Social Change (USA); and Futuribles (France).

${ }^{9}$ See http://aqaljournal.integralinstitute.org/public/Default.aspx.

${ }^{10} \mathrm{Vol} 1$ no 1 contained material dealing with serious 'depth' topics: "axioms for a living universe" and "evolution of the ecology of mind."

${ }^{11}$ Also Butter et al. (2008). 